\title{
Rosiglitazone Ameliorates Monocrotaline-Induced Pulmonary Arterial Hypertension in Rats by Regulating the Extracellular Matrix Remodelling
}

\author{
XIAOFANG WANG, YUNJIAN ZHANG* ${ }^{*}$ J. GUO' ${ }^{1}$ AND J. SHI ${ }^{2}$ \\ Department of Respiratory and Critical Care Medicine, Beijing Jishuitan Hospital, Beijing 100035, China; 1Department of \\ Respiratory Medicine, Beijing Tsinghua Changgung Hospital, Beijing 102218, China; 2Department of Respiratory Medicine, \\ Peking Union Medical College Hospital, Beijing 100730, China
}

Wang et al.: Rosiglitazone and Monocrotaline-Induced Pulmonary Arterial Hypertension in Rats

To investigate the effect of rosiglitazone on pulmonary arterial hypertension in rats monocrotaline $(60 \mathrm{mg} / \mathrm{kg})$-induced pulmonary arterial hypertension was developed in male Sprague Dawley rats. Pulmonary arterial hypertensive rats were given different treatments ( $\mathrm{n}=8$ per group), such as saline, low dose rosiglitazone $(2.5 \mathrm{mg} / \mathrm{kg})$, and high-dose rosiglitazone $(5 \mathrm{mg} / \mathrm{kg})$ via oral gavage once a d for $21 \mathrm{~d}$. Sprague Dawley rats $(\mathrm{n}=8)$ injected subcutaneously with physiological saline were also included as the sham control (group $N$ ), which received saline as the treatment. When the $21 \mathrm{~d}$ treatment regimens were completed, the mean pulmonary artery pressure was measured through right heart catherization. Hematoxylin and eosin staining was done to examine the histological changes of lung tissues, with the tunica media thickness of small pulmonary arteries were evaluated by Elastin Van Gieson staining. The medial thickness relative to the vascular diameter was determined. The degree of muscularization and $\alpha$-smooth muscle actin density of non-muscularized pulmonary arterioles were also assessed. The protein expression of peroxisome proliferator-activator receptor- $\gamma$, metalloproteinase matrix metallopeptidases-2 and matrix metallopeptidases-9 in lungs was studied using immunohistochemistry. The expression of peroxisome proliferator-activator receptor- $\gamma$, matrix metallopeptidases- 2 and matrix metallopeptidases-9 and tissue inhibitor of metalloproteinase-1 genes in lungs was assessed using fluorescent quantitative polymerase chain reaction. The activity of matrix metallopeptidases- 2 and matrix metallopeptidases-9 was determined using gelatin zymography. Treatment of pulmonary arterial hypertension rats with low-dose and high-dose rosiglitazone significantly reduced mean pulmonary artery pressure compared to saline treatment (saline $37 \pm 5$, low-dose rosiglitazone $28 \pm 4$ and high-dose rosiglitazone $27 \pm 4 \mathrm{mmHg}$ ). Rosiglitazone treatment also reduced \% wall thickness compared to the control (saline, $45.5 \pm 5.5$, low-dose rosiglitazone 16.7 \pm 1.7 and high-dose rosiglitazone 13.1 $\pm 3.9 \%$ ). Rosiglitazone treatment also decreased muscularization and $\alpha$-smooth muscle actin density of pulmonary arterioles (muscularization: saline, $67.55 \pm 2.95 \%$; low-dose rosiglitazone, $54.73 \pm 2.39 \%$; high-dose rosiglitazone, $51.74 \pm 2.67 \%$; $\alpha$-smooth muscle actin density: saline, $0.49 \pm 0.03$; low-dose, $0.38 \pm 0.03$; high-dose, $0.31 \pm 0.02$ ). Compared to the pulmonary arterial hypertension rats receiving saline alone, those treated with low-dose and high-dose rosiglitazone presented significantly higher peroxisome proliferator-activator receptor- $\gamma$ expression and lower metallopeptidases-2, metallopeptidases- 9 and tissue inhibitor of metalloproteinase-1 expression in lung tissues. Low-dose and high-dose rosiglitazone treatment also reduced metallopeptidases-9 activity in lung tissues compared to the saline-treated pulmonary arterial hypertension rats. Early administration of rosiglitazone might delay the progression of monocrotaline-induced pulmonary arterial hypertension in rats. The underlying mechanism could be attributed to the reactivation of peroxisome proliferatoractivator receptor- $\gamma$ signaling that modulated metallopeptidases- 9 activity and in turn extracellular matrix remodeling.

Key words: Monocrotaline, pulmonary arterial hypertension, rosiglitazone, extracellular remodelling

Pulmonary arterial hypertension $(\mathrm{PAH})$ is a progressive disease with a characteristic of increased pulmonary vascular resistance. It is believed that the increased resistance was attributed to the pulmonary vascular

*Address for correspondence

E-mail: zhangyjian@126.com 
remodeling. Antiremodelling therapy has thus become an important treatment strategy for PAH. The process of pulmonary vascular remodelling involved the migration, infiltration, and proliferation of smooth muscle cells (SMCs) and fibroblasts, as well as the muscularization of the distal part of the pulmonary arterial tree. Another characteristic of severe PAH is the formation of a layer of myofibroblasts and extracellular matrix (ECM) between the endothelium and the internal elastic lamina ${ }^{[1,2]}$. Evidences showed that dynamics of ECM played a critical role in vascular remodeling ${ }^{[3]}$. Matrix metalloproteinases (MMPs) are regulators of EMC degradation and tissue inhibitor of metalloproteinases (TIMPs) are key inhibitors of MMP activity. Both MMPs and TIMPs are important regulators for the remodelling of $\mathrm{ECM}^{[4,5]}$. Studies reported that patients or animal models with pulmonary hypertension had aberrant expressions of MMP-2, MMP-9, and TIMPs ${ }^{[6,7]}$, indicating a critical role of MMPs during pulmonary vascular modeling and PAH progression.

Peroxisome proliferator activated receptor- $\gamma$ (PPAR- $\gamma$ ) belongs to the nuclear hormone receptor superfamily and is involved in the regulation of glycolipid metabolism, inflammatory response and cell proliferation/ apoptosis $^{[8,9]}$. Studies have shown that PPAR- $\gamma$ inhibited the expression of MMPs, in which the associations with MMP-2 and MMP-9 were frequently reported ${ }^{[10-17]}$. In vivo studies of atherosclerosis, hypertension, and cardiac remodelling, as well as in vitro studies of SMCs, showed that the therapeutic effects of PPAR- $\gamma$ agonist were exerted through the regulation of MMPs and $\mathrm{TIMP}^{[10,11,14]}$. It was reported that PPAR- $\gamma$ expression was reduced in lungs from patients with pulmonary hypertension ${ }^{[18]}$ and the PPAR- $\gamma$ agonist could inhibit or reverse the progression of $\mathrm{PAH}^{[19-23]}$. However, the underlying mechanism of PPAR- $\gamma$ on pulmonary vascular remodelling remains to be elucidated.

Rosiglitazone is a PPAR- $\gamma$ agonist of the thiazolidinedione (TZD) class. It has a hypoglycemic action and used to treat diabetes, as well as effects on inflammation, cell proliferation, and metabolism ${ }^{[24]}$. Recent studies showed that TZDs including pioglitazone, troglitazone and rosiglitazone have reduced pulmonary hypertension and pulmonary vascular remodelling in animal models of hypertension induced by monocrotaline or hypoxia ${ }^{[25-27]}$. Several studies suggested that the improvement of pulmonary vascular remodelling by TZDs was through regulating many factors such as BMP-2, HO-1, ET-1, VEGF,
5-HT, NF- $\kappa \mathrm{B}, \mathrm{TGF}-\beta^{[23,28-33]}$. However, there have been limited studies on the mechanism through MMPs.

It was hypothesized that the reversal of pulmonary vascular remodelling by rosiglitazone was through activation of PPAR- $\gamma$, as well as regulating MMPs and remodelling of ECM. In this study, a rat model of PAH induced by monocrotaline (MCT) was used and the effects of rosiglitazone on PPAR- $\gamma$, MMP-2, MMP-2 and TIMP-1 were investigated.

\section{MATERIALS AND METHODS}

\section{Animal grouping and treatment:}

Thirty-two male SPF-grade Sprague Dawley (SD) rats, aged $6 \mathrm{w}$ with body weight of 170-190 g, were purchased from Beijing Vital River Laboratory Animal Technology Co. Ltd (Beijing, China). The rats were maintained in a humidity-controlled facility with a 12-h light/dark cycle at ambient temperature and had $\mathrm{ad}$ libitum access to sterilized chow and water. Rats were acclaimed for 4 to $5 \mathrm{~d}$ before starting the study.

Rats were randomly divided into experimental and control groups ( $n=8$ per group). To induce $\mathrm{PAH}$, rats were subcutaneously injected with $60 \mathrm{mg} / \mathrm{kg}$ MCT (Sigma, St. Louis, MO, USA). Sham-operated control rats received subcutaneous injection of physiologic saline. Treatments were initiated on the day of MCT injection and were given via oral gavage once a $\mathrm{d}$ for 21 d. PAH rats of the control group (group M) were given physiologic saline. The published effective dose of rosiglitazone ranged from 0.5 to $10 \mathrm{mg} / \mathrm{kg}$ depending on the route of administration, dose frequency, and nature of disease models ${ }^{[30,33]}$. In view of this, 2 dose levels of rosiglitazone were tested in this study. PAH rats of the low (group MRL) and high dose (group MRH) groups received orally 2.5 and $5.0 \mathrm{mg} / \mathrm{kg}$ rosiglitazone maleate (Avandia, GlaxoSmithKline, UK), respectively. The sham-operated rats (group $\mathrm{N}$ ) were treated with physiologic saline. All rats were closely monitored throughout the study; body weights measured before and 7,14 , and $21 \mathrm{~d}$ after the commencement of treatment. Animal use and study design were approved by the Beijing Jishuitan Hospital Institutional Animal Care and Use Committee.

\section{Lung tissue collection:}

After the treatment was completed, rats were anaesthetized with $1200 \mathrm{mg} / \mathrm{kg}$ urethane. Right lungs were first perfused with physiologic saline and then harvested and stored in liquid nitrogen until use. Left 
lungs were fixed with $4 \%$ paraformaldehyde for histological studies. After lung tissue collection, rats were euthanized by cervical dislocation. Animal deaths were confirmed with the lack of corneal reflex, and the absence of respiration and heartbeat over a period of more than $5 \mathrm{~min}$.

Assessment of pulmonary hemodynamics and right ventricular hypertrophy index (RVHI) was done by isolating the right jugular vein of the rat under anesthesia, A $0.9-\mathrm{mm}$ catheter connected to a pressure monitor, was inserted and advanced into the right ventricle and then into the pulmonary trunk to measure right ventricular systolic pressure (RVSP) and pulmonary artery mean pressure (mPAP). RVHI was determined after complete removal of the heart, right ventricle, left ventricle and the ventricular septum were separated and individually weighted. RVHI was expressed as the ratio of weight of the right ventricular wall and that of the free left ventricular wall and ventricular septum.

\section{Pulmonary arteriole measurement:}

Elastin Van Gieson-stained lung sections were observed under light microscope with a magnification power of $400 \times$. Thirty pieces of pulmonary arterioles with a diameter of 50 to $150 \mu \mathrm{m}$ were randomly selected from each stained section. The wall thickness (WT) of the pulmonary arterioles and the vascular outer diameter (ED) were determined using Image-Pro Plus 6.0 image acquisition and processing system. Percent WT was calculated as $(2 \times \mathrm{WT} / \mathrm{ED}) \times 100$.

\section{Assessment of muscularization of arterioles:}

Extension of $\alpha$-SMA-positive smooth muscle cells into non-muscular arterioles of the alveolar wall was examined. Under the light microscope, 20 highpower fields $(400 \mathrm{X})$ were randomly selected. Thirty to sixty arterioles of a diameter of 15 to $50 \mu \mathrm{m}$ in the acinus were then counted. According to the degree of $\alpha$-SMA staining, the muscularization of arterioles was categorized as muscular, partially muscular and non-muscular. The degree of muscularization was then calculated as \% muscular and partially muscular arterioles in total observed arterioles. The optical density of $\alpha$-SMA staining was also determined at the same optical fields for arteriole muscularization assessment.

\section{Lung immunohistochemical staining:}

The expression of $\alpha$-SMA, PPAR $\gamma$, MMP-2 and MMP9 in the lung was studied using immunohistochemical staining. Left lung tissues were formalin-fixed, dehydrated and paraffin-embedded. To perform immunohistochemistry, sections with thickness of $4 \mu \mathrm{m}$ were prepared, rehydrated and subjected to antigen retrieval. Tissue slides were then stained with mouse monoclonal anti- $\alpha$-SMA antibody (Boster Biological Technology, Wuhan, China), rabbit polyclonal antibodies against PPAR $\gamma$, MMP-2 or MMP-9 (Bioss Antibodies, Beijing, China) at room temperature for $1 \mathrm{~h}$. After incubation with respective HRP-conjugate and washing, signals were developed using 3,3'-diaminobenzidine from Boster Biological Technology.

\section{Gene expression study:}

Total RNA was extracted from the right lung using TriZol/chloroform approach. After that, the total RNA was used as a template for the synthesis of first-strand cDNA. The amounts of PPAR $\gamma$, MMP-2, MMP-9 and TIMP-1 transcripts were quantitated using real-time PCR. Gene amplification was done using SYBR Green Master Mix (Bio-Rad Laboratories, Hercules, CA, USA) in Bio-Rad Chromo 4 system with oligonucleotides. The reaction mixtures were subjected to an initial denaturation at $95^{\circ}$ for $30 \mathrm{~s}$, which was followed by 35 cycles of denaturation $\left(95^{\circ}\right.$ for $\left.15 \mathrm{~s}\right)$ and extension $\left(60^{\circ}\right.$ for $30 \mathrm{~s})$. The gene level of each amplified target was then quantified using $2^{-\Delta \Delta C t}$ method. Housekeeping gene $\beta$-actin was included as the internal loading control.

\section{Metalloproteinase activity assay:}

Protein extracted from the right lungs was resolved using electrophoresis and then assayed for bioactivity using gelatin zymography. Images were captured with an imaging instrument from Tanon (Shanghai, China). The cumulative optical density of the bands was also collected from quantitative analysis.

\section{Statistical analysis:}

All data were analysed using statistical software SPSS version 23.0. Counting data were expressed in terms of rate or composition ratio. Measurement data were presented as mean $\pm \mathrm{SD}$. Paired t-test and oneway analysis of variance were used for comparison between groups. Statistically significant comparison was indicated by p-value $*<0.05, * *<0.01$.

\section{RESULTS AND DISCUSSION}

During the in-live study, except in the low-dose treatment group, all rats survived. In the low-dose treatment 
group, one rat died of experimental procedure related to oral gavage with another one died of unknown reasons. Before the PAH induction by MCT injection, all the rats showed comparable body weight (Table 1). However, 7 , 14 , and $21 \mathrm{~d}$ after the MCT injection, the body weights of PAH rats of the model, low-dose treatment and high-dose treatment groups were significantly lower than those of the sham-operated rats. There were no significant differences in body weights between PAH rats of different treatment groups.

The mPAP, RVSP, and RVHI of all rats were determined (Table 2). The average mPAP, RVSP, and RVHI of the model rats (group $\mathrm{M}$ ) were all significantly higher than those of the sham control. Treatment of PAH rats with low dose and high dose rosiglitazone reduced significantly mPAP, RVSP, and RVHI comparing to the model rats receiving no treatment. High-dose rosiglitazone apparently further reduced the average

TABLE 1: EFFECT OF ROSIGLITAZONE ON THE BODY WEIGHTS OF PAH RATS

\begin{tabular}{lcccc}
\hline Group & Week 0 & Week 1 & Week 2 & Week 3 \\
\hline Sham $(n=8)$ & $227 \pm 9$ & $287 \pm 12$ & $331 \pm 15$ & $375 \pm 19$ \\
PAH $(n=8)$ & $227 \pm 9$ & $261 \pm 17^{\#}$ & $276 \pm 24^{\#}$ & $319 \pm 29^{\#}$ \\
MRH $(n=8)$ & $226 \pm 4$ & $268 \pm 8^{*}$ & $275 \pm 15^{\#}$ & $328 \pm 14^{\#}$ \\
MRL $(n=8)$ & $228 \pm 7$ & $261 \pm 8^{\#}$ & $284 \pm 11^{\#}$ & $329 \pm 12^{\#}$ \\
\hline Al
\end{tabular}

All values are mean $\pm S D,{ }^{\sharp} \mathrm{p}<0.01,{ }^{*} \mathrm{p}<0.05$, comparing to the sham control

TABLE 2: EFFECT OF ROSIGLITAZONE ON MPAP, RVSP, AND RVHI OF PAH RATS

\begin{tabular}{llll}
\hline Group & mPAP $(\mathrm{mmHg})$ & RVSP $(\mathrm{mmHg})$ & RVHI \\
\hline Sham $(\mathrm{n}=8)$ & $17.13 \pm 3.30$ & $40.33 \pm 5.77$ & $0.25 \pm 0.02$ \\
PAH $(\mathrm{n}=8)$ & $37.00 \pm 4.98^{\#}$ & $67.04 \pm 4.87^{*}$ & $0.40 \pm 0.02^{+}$ \\
MRH $(\mathrm{n}=8)$ & $26.88 \pm 3.55^{\#}$ & $50.09 \pm 5.61^{*}$ & $0.33 \pm 0.03^{+\bullet}$ \\
MRL $(\mathrm{n}=6)$ & $28.29 \pm 3.60^{\#}$ & $55.71 \pm 4.85^{*}$ & $0.33 \pm 0.02^{+\bullet}$ \\
\hline
\end{tabular}

All values are mean \pm SD, mPAP: $\# p<0.01$ comparing to sham; $\star \mathrm{p}<0.01$ comparing to PAH. RVSP: ${ }^{*} \mathrm{p}<0.01$ comparing to sham; $\mathrm{p}<0.05$ comparing to sham; $\varnothing p<0.01$ comparing to PAH. RVHI: $+p<0.01$ comparing to sham; $\bullet p<0.01$ comparing to PAH
mPAP and RVSP comparing to the low-dose. However, the differences between two groups were not statistically significantly.

The pulmonary artery of the sham control rat remained intact with no signs of infiltration of inflammatory cells as revealed by H\&E staining (fig. 1). In the control PAH rats receiving no treatment, the pulmonary artery was significantly thickened, narrowing the lumen of the artery. Infiltrating inflammatory cells were observed around the vessels. The acinar pulmonary arterioles were also significantly muscularized. In the PAH rats treated with low-dose and high-dose rosiglitazone, the pulmonary artery walls were slightly thickened with little infiltration of inflammatory cells. The acinar pulmonary arterioles were also mildly muscularized.

The medial layers of the pulmonary arterioles of rats were examined using ET+VG staining (fig. 2A). Both the external and internal elastic laminas of the sham control rats were smooth. In the model rat, the external and internal elastic laminas were squeezed into a wavy shape. Significant hypertrophy of the medial smooth muscle layer was also noted. In the rats treated with lowdose and high-dose rosiglitazone, the medial smooth muscle layers showed only mild hypertrophy. The external and internal elastic laminas of the pulmonary arterioles of these rats were not compressed.

All PAH rats displayed elevated WT \% comparing to the sham-operated rats, of which the differences were statistically significant $(\mathrm{p}<0.01$, fig. $2 \mathrm{~B}$ ). Treatment of $\mathrm{PAH}$ rats with low-dose and high-dose rosiglitazone significantly reduced WT \% comparing to their counterparts receiving no treatment $(\mathrm{p}<0.01)$. The WT $\%$ of $\mathrm{PAH}$ rats receiving high-dose rosiglitazone was comparable to those of the sham control. The WT \% of PAH rats treated with low-dose rosiglitazone was

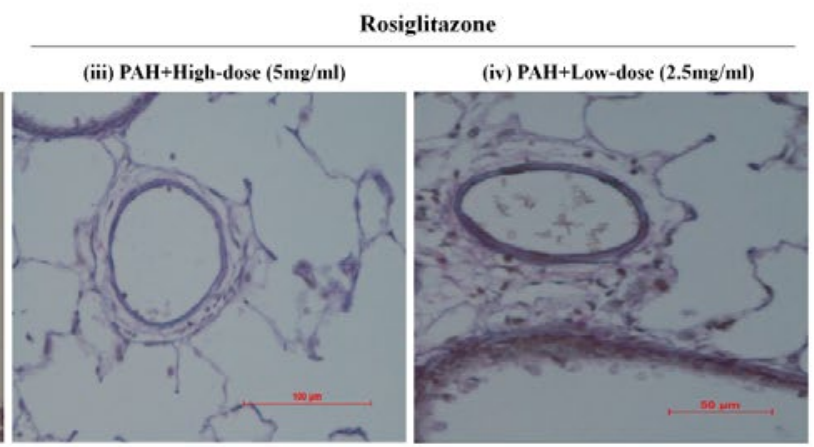

Fig. 1: Effect of rosiglitazone on inflammatory cell infiltration and arteriole wall muscularization of PAH rats

(A) Pulmonary arterioles of rats receiving Sham-operation only; PAH induction and saline; PAH induction and high-dose rosiglitazone (5 mg/kg); and PAH induction and low-dose rosiglitazone (2.5 mg/kg). (B) Acinar pulmonary arterioles of rats receiving Sham-operation only; PAH induction and saline; PAH induction and high-dose rosiglitazone (5 mg/kg); and PAH induction and low-dose rosiglitazone $(2.5 \mathrm{mg} / \mathrm{kg})$. Treatment with rosiglitazone was demonstrated to ameliorate the infiltration of inflammatory cells and to reduce the degree of muscularization of arteriole walls. Shown is the representative set of data. Magnification of $\times 400$. 
still significantly higher than those of the sham control $(\mathrm{p}<0.05)$.

Comparing to the sham control rats, PAH rats of different treatment groups displayed significantly higher percentages of arteriole muscularization as well as $\alpha$-SMA optical density (Table 3 ). Treatment of PAH rats with low-dose and high-dose rosiglitazone significantly reduced arteriole muscularization $(\mathrm{p}<0.01)$ and $\alpha$-SMA optical density $(\mathrm{p}<0.01)$ comparing to their counterparts receiving no treatment. PAH rats received high-dose rosiglitazone treatment presented lower $\alpha$-SMA optical density $(\mathrm{p}<0.01)$ comparing to the counterpart rats treated with low-dose rosiglitazone, despite the difference in arteriole muscularization was not statistically significant ( $\mathrm{p}>0.05$ ).

Upon immunohistochemical staining, PPAR $\gamma$-positive cells were majorly detected in the intima of pulmonary

TABLE 3: EFFECT OF ROSIGLITAZONE ON THE MUSCULARIZATION OF PULMONARYARTERIOLES OF PAH RATS

\begin{tabular}{lcc}
\hline Group & $\begin{array}{c}\text { Percentage } \\
\text { muscularization (\%) }\end{array}$ & $\begin{array}{c}\text { a-SMA optical } \\
\text { density }\end{array}$ \\
\hline Sham $(n=8)$ & $19.91 \pm 2.27$ & $0.22 \pm 0.04$ \\
PAH $(n=8)$ & $67.55 \pm 2.95^{\#}$ & $0.49 \pm 0.03^{\star}$ \\
MRH $(n=8)$ & $51.74 \pm 2.67^{\#-}$ & $0.31 \pm 0.02^{\star}$ \\
MRL $(n=6)$ & $54.73 \pm 2.39^{\#-}$ & $0.38 \pm 0.03^{\star}$ \\
\hline
\end{tabular}

All values are mean $\pm S D$, ${ }^{*} p<0.01$ comparing to sham; $\square p<0.01$ comparing to PAH. a-SMA optical density: $\mathbf{\Delta} \mathrm{p}<0.01$ comparing to sham; $p<0.01$ comparing to PAH; $\bullet p<0.05$ comparing to MRH. blood vessel. The brownish yellow signal of PPAR $\gamma$ was localized in the cytoplasmic compartments and the nuclei of the cells (fig. 3). In the sham control rats PPAR $\gamma$ signal was detected in the intima of pulmonary arterioles. PAH induction suppressed the expression of PPAR $\gamma$, while treatment with low-dose and high-dose rosiglitazone could restore PPAR $\gamma$ in the arterioles.

The mRNA levels of MMP-2, MMP-9, and TIMP-1 in lung tissues were also studied (Table 4). PAH induction significantly increased MMP-2, MMP-9, and TIMP1 mRNA levels comparing to the sham control rats $(p<0.01)$. Treatment of PAH with low-dose and highdose rosiglitazone led to substantial decreases in all the three gene targets comparing to the $\mathrm{PAH}$ rats receiving no treatment $(\mathrm{p}<0.01)$. The MMP-9 gene expression of model rats receiving high-dose rosiglitazone was significantly lower than that of rats treated with lowdose rosiglitazone $(\mathrm{p}<0.05)$.

The underlying pathogenesis of PAH is attributed to the remodelling of pulmonary vascular, of which the key manifestations include pulmonary neointimal formation, intimal fibrosis, mesenteric hypertrophy, formation of plexiform lesions, aberrant changes in extracellular matrix (ECM), and abnormal depositions in the pulmonary vascular wall. All these changes are associated with dysfunction of vascular endothelial cells (EC), activation of SMCs and fibroblasts and
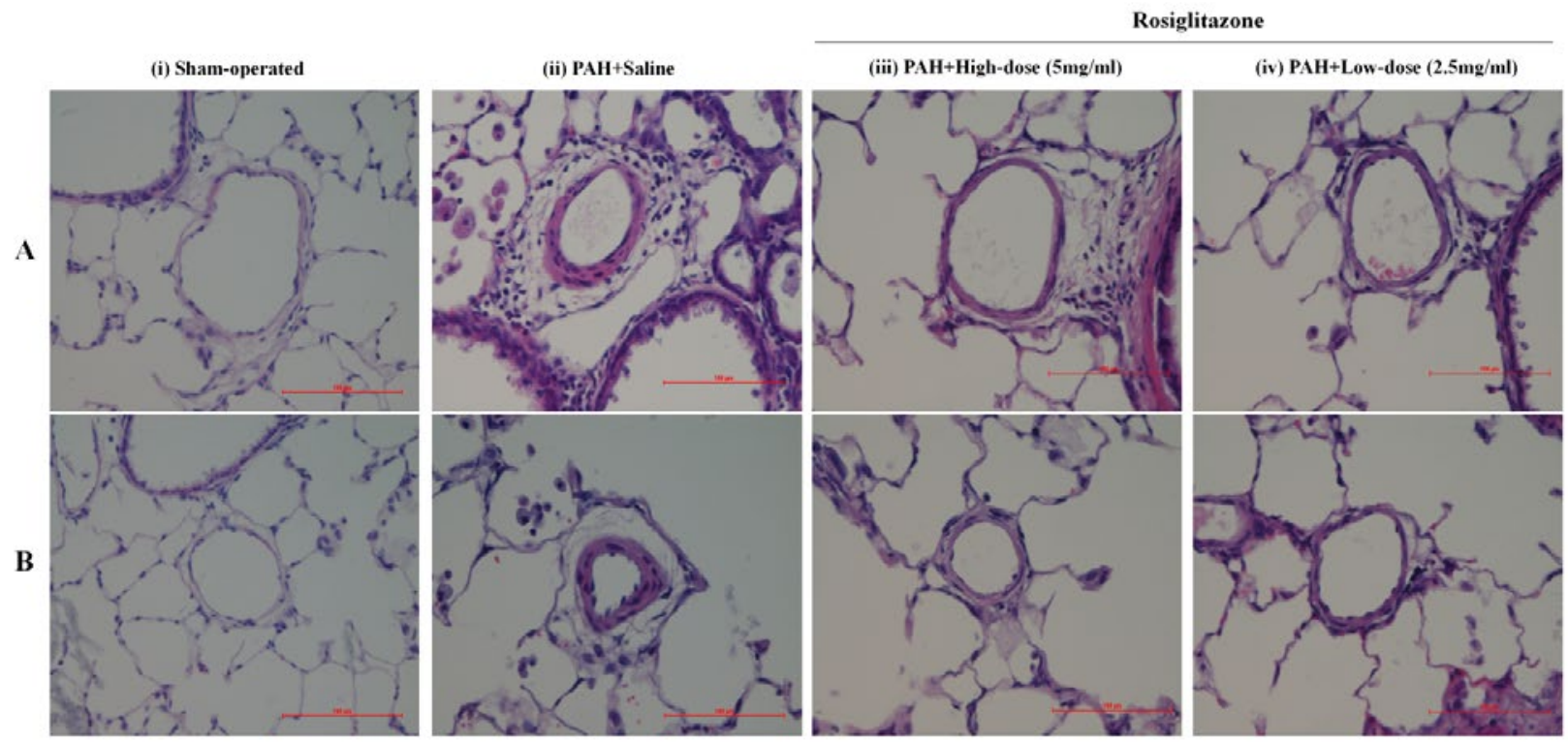

Rosiglitazone

Fig. 2: Effect of rosiglitazone on the thickness of the medial smooth muscle layer of PAH rats

(A) ET+VG staining of rats receiving different treatments: Sham-operation only; PAH induction and saline; PAH induction and high-dose rosiglitazone $(5 \mathrm{mg} / \mathrm{kg})$; and $\mathrm{PAH}$ induction and low-dose rosiglitazone $(2.5 \mathrm{mg} / \mathrm{kg})$. Staining results suggested that PAH caused significant hypertrophy of the medial smooth muscle layer of rat arterioles. Treatment with rosiglitazone could significantly prevent the hypertrophy of the smooth muscle. Shown is the representative set of data. Magnification $\times 400$. (B) The medial thickness of pulmonary arterioles of rats with MCT-induced PAH was quantified as WT \% and compared. Rosiglitazone treatment, both low and high doses, could reduce the medial thickness of pulmonary arterioles in rats. ${ }^{*} p<0.01$ when compared to the sham control; ${ }^{*} \mathbf{p}<0.01$ when compared to PAH rats treated with saline alone; ${ }^{* *} \mathbf{p}<0.05$ when compared to the sham control. 


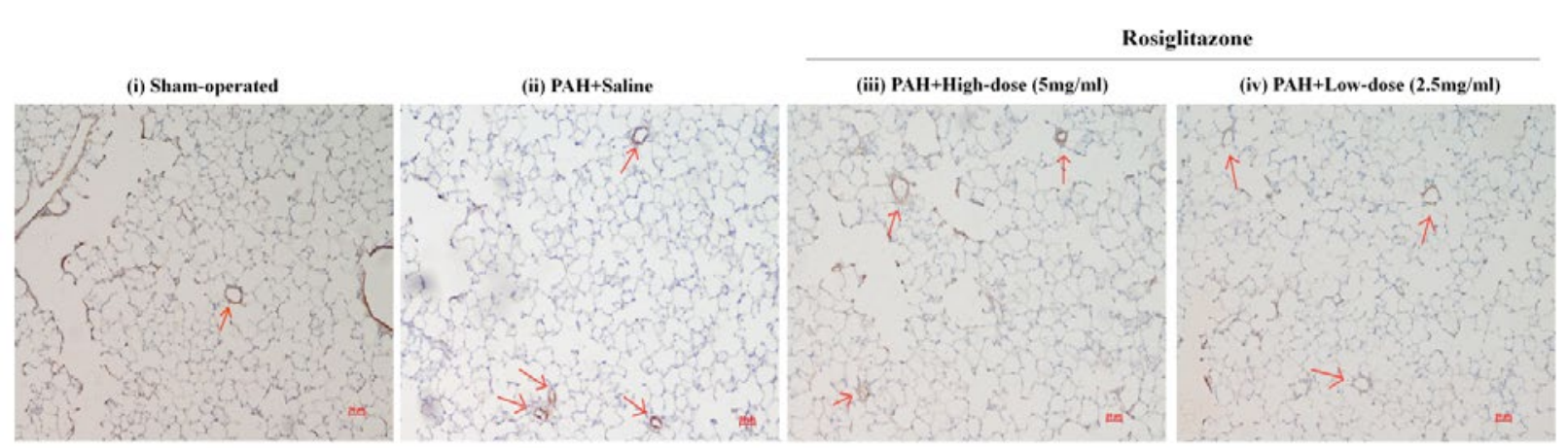

Fig. 3: Effect of rosiglitazone on the gene and protein expression of PPAR $\gamma$ in the lungs of PAH rats Immunohistochemistry was performed to examine protein expression of PPAR $\gamma$ in rat lungs. PAH suppressed PPAR $\gamma$ expression in the lungs of rats with PAH. Treatment with rosiglitazone, both low and high doses, could restore PPAR $\gamma$ expression as localized by the brownish-red reactivity signals. Shown is the representative set of data. Magnification $\times 400$.

TABLE 4: EFFECT OF ROSIGLITAZONE ON THE MRNA EXPRESSION OF MMP-2, MMP-9 AND TIMP-1 OF PAH RATS

\begin{tabular}{lccc}
\hline Group & MMP-2 mRNA $\left(2^{-\Delta \Delta c t}\right)$ & MMP-9 mRNA $\left(2^{-\Delta \Delta c t}\right)$ & TIMP-1 mRNA $\left(2^{-\Delta \Delta C t}\right)$ \\
\hline Sham $(n=8)$ & $0.96 \pm 0.08$ & $0.96 \pm 0.06$ & $1.02 \pm 0.14$ \\
PAH $(n=8)$ & $3.30 \pm 0.39^{\#}$ & $7.07 \pm 0.54^{*}$ & $3.52 \pm 0.44^{*}$ \\
MRH $(n=8)$ & $2.00 \pm 0.20^{\#}$ & $3.89 \pm 0.65^{* \Delta}$ & $2.20 \pm 0.34^{*}$ \\
MRL $(n=6)$ & $2.37 \pm 0.17^{\#}$ & $5.00 \pm 0.71^{* \Delta}$ & $2.58 \pm 0.36^{* \bullet}$ \\
\hline
\end{tabular}

All values are mean \pm SD, MMP-2 mRNA: ${ }^{\#} p<0.01$ comparing to sham; $p<0.01$ comparing to PAH. MMP-9 mRNA: ${ }^{*} p<0.01$ comparing to sham; $\Delta p<0.01$ comparing to PAH; $\nabla p<0.05$ comparing to MRH. TIMP-1 mRNA: $\bullet p<0.01$ comparing to sham; $\bullet p<0.01$ comparing to PAH

interactions between ECs, SMCs, and fibroblasts. In this study, the therapeutic effect of rosiglitazone was investigated in a clinically relevant rat model of PAH induced by MCT. Three w after MCT injection, right heart catheterization showed that substantial elevations in the mPAP, RVSP, and RVHI of the model rats. The changes in pulmonary hemodynamics were accompanied with obvious pulmonary remodelling characterized with intimal hyperplasia of pulmonary arterioles and muscularization of acinar arteries. Early administration of rosiglitazone could significantly lower the elevation of mPAP, RVSP, and RVHI induced by MCT, ameliorating the hyperplasia of pulmonary arterioles and degree of muscularization of acinar arteries in PAH rats.

In recent years, the ECM-derived signals have been shown important to the formation and function of blood vessel by their effects on endothelial and smooth muscle cells ${ }^{[34]}$. MMPs represent a family of zinccontaining proteases that are capable of degrading ECM. These can shape vascular remodelling by affecting the proliferation, migration, and subsequent neointimal formation of SMCs $^{[35]}$. TIMPs are endogenous inhibitors of MMPs. The balance between the activation and inactivation of MMP, which is tightly regulated by TIMPs, are essential to the homeostasis of vascular matrix. Indeed, MMP-2 and -9 and TIMP1 have been implicated in the vascular remodelling of
MCT-induced PAH in rat ${ }^{[36-38]}$. Lepetit et al. reported that in patients with IPAH, the MMP-2 activity and TIMP-1 expression were increased, which might be related to the proliferation and migration processes of SMCs $^{[7]}$. Serum MMP-9 levels in patients with IPAH and hereditary PAH were elevated ${ }^{[39]}$. In MCT-induced PAH model, MMP-2 and MMP-9 were significantly elevated in terms of expression and activity ${ }^{[36]}$. The increased expression of MMP-9 in lung tissues was associated with right ventricular (RV) hypertrophy and RV failure in model rats ${ }^{[40]}$. In line with these findings, this study showed that compared with the sham control rats, the mRNA expression and activity of MMP-2 and MMP-9 in the lung tissues of PAH rats were significantly increased, implicating the involvement of these MMPs in the development of pulmonary vasculopathy of PAH. The expression of TIMP-1 mRNA in lung tissues was also elevated. This upregulation might serve as a negative feedback mechanism to prevent MMPs from hyperactivation.

In addition to MMPs and TIMPs, PPAR $\gamma$, a member of the transcription factor nuclear receptor superfamily, is also affected in PAH. Studies showed that the expression of PPAR $\gamma$ gene and protein in lung tissues of patients with severe PAH and animal models of PAH was significantly suppressed. The expression in the plexiform lesions of PAH could be totally absent ${ }^{[18,32]}$. A large body of evidence indicated the 
modulating effects of PPAR $\gamma$ on the multiple signaling pathways involved in the pathogenesis of PAH. PPAR $\gamma$ ligands were demonstrated to alleviate the pulmonary vascular remodelling in animal models of $\mathrm{PAH}^{[25-}$ 31,33,41]. In vitro study also illustrated the relaxation of pulmonary artery by PPAR $\gamma$ agonists in a time and dose-dependent manner, of which the effect could be attenuated by PPAR $\gamma$ antagonists ${ }^{[42]}$. In accordance with previous studies, the present work also demonstrated the down-regulated expression of PPAR $\gamma$ mRNA in the pulmonary arterioles of rats with MCT-induced PAH, and treatment of PAH rats with low and high doses of rosiglitazone could restore the gene expression of PPAR $\gamma$ in lung tissues. The high-dose treatment achieved an apparently higher PPAR $\gamma$ restoration than the low-dose, suggesting the pulmonary vasoprotective effect of rosiglitazone could be dose-dependent.

Recent in vitro and in vivo findings from multiple disease models such as hypertension, vascular injury, ventricular remodelling, central nervous system damage, and malignant tumors collectively pointed to a notion that PPAR $\gamma$ agonists could reduce the expression of MMPs ${ }^{[9,10]}$. Crossno et al. showed in a rat model of hypoxia-induced PAH that rosiglitazone could suppress the expression and activity of MMP-9 in rats lung tissues, improving collagen deposition on pulmonary vascular wall, restoring the integrity of blood vessels $^{[17]}$. Interestingly, at the same time, rosiglitazone could increase the expression of low-molecular weight MMP-2 in the lung tissues of PAH rats. This lowmolecular weight MMP-2 was the fragment resulting from the hydrolysis of MMP-2 by other proteases and was believed to restore normal vascular architecture by degrading excessive collagen of the ECM. Echo with the previous findings, the present study clearly showed that early intervention with rosiglitazone could significantly reduce MMP-2, MMP-9, and TIMP1 mRNA expression in the lung tissues of PAH rats. The activity of MMP-9 but not MMP-2 was also suppressed. The regulation of MMPs is twofold, at transcriptional and post-translational levels. MMPs are expressed as inactive zymogens and become active only after specific activation cleavage. Therefore, although rosiglitazone reduced the mRNA expression of MMP-2, the treatment did not significantly suppress the activity of MMP-2 in the model.

In the current study design, rats were administered rosiglitazone on the $\mathrm{d}$ when $\mathrm{MCT}$ was injected to induce PAH. In this context, the action of rosiglitazone would likely be preventive. The findings of the present study collectively suggested that rosiglitazone could delay the MCT-induced pulmonary vasculopathy in PAH rats by activating PPAR $\gamma$ which in turn modulating MMPs and TIMP-1. The signaling pathways involved would be potential therapeutic targets for PAH treatment. Nevertheless, the detailed mechanism of action of MMPs in vascular remodelling has remained to be fully elucidated. The use of a proper positive control e.g. sildenafil will benefit the further validation of the present findings by assessing their correlations between pharmacological effects and mechanisms. To provide a more comprehensive picture of the action of rosiglitazone on $\mathrm{PAH}$, the changes in pulmonary perivascular fibrosis, collagen concentration and fibrosis markers will be assessed. In addition, since the endothelial dysfunction closely links to arterial hypertension, the anti-proliferative properties of rosiglitazone will be evaluated in primary pulmonary artery smooth muscle cells and in vivo. Rosiglitazone has been used for the treatment of diabetes; therefore, it is of interest to explore the therapeutic effect of rosiglitazone on cells exposed to high glucose concentration and in diabetic rats with PAH. The protective effects of PPAR $\gamma$ agonists in PAH will also be validated using specific antagonists of PPAR $\gamma$. Current medication for PAH is related to the function of key pathways such as prostanoids, adenyl cyclase and endothelin receptor, of which the common element is calcium. Dynamic changes in intracellular calcium play critical roles in regulating vascular smooth muscle contractility and hence blood flow and pressure $^{[43]}$. The efficacy of ambrisentan and bosentan are the currently used drugs for PAH. Combining these drugs with rosiglitazone may cause synergistic effect, providing multiple benefits thus improving the quality of life of patients suffering from PAH. It would be of interest to investigate the effect of rosiglitazone or other TZDs on calcium influx. Two rats from the lowdose treatment group died during the study. One of the deaths was due to the procedure related to oral gavage. The procedure will be further refined to minimize the number of death among rats in future validation studies.

\section{Acknowledgements:}

This work was supported by Project of Beijing Municipal Science and Technology Commission (Z141107002514153).

\section{Conflict of interests:}

The authors declared no conflict of interest. 


\section{REFERENCES}

1. Morrell NW, Adnot S, Archer SL, Dupuis J, Jones PL, MacLean $\mathrm{MR}$, et al. Cellular and molecular basis of pulmonary arterial hypertension. J Am Coll Cardiol 2009;54:S20-31.

2. Humbert M, Morrell NW, Archer SL, Stenmark KR, MacLean MR, Lang IM, et al. Cellular and molecular pathobiology of pulmonary arterial hypertension. J Am Coll Cardiol 2004;43:S13-24.

3. Majesky MW, Dong XR, Hoglund V, Daum G, Mahoney Jr WM. The adventitia: a progenitor cell niche for the vessel wall. Cells Tissues Organs 2012;195:73-81.

4. Novotná J, Herget J. Possible role of matrix metalloproteinases in reconstruction of peripheral pulmonary arteries induced by hypoxia. Physiol Res 2002;51:323-34.

5. Cowan KN, Jones PL, Rabinovitch M. Elastase and matrix metalloproteinase inhibitors induce regression, and tenascin- $\mathrm{C}$ antisense prevents progression, of vascular disease. J Clin Invest 2000;105:21-34.

6. Chelladurai P, Seeger W, Pullamsetti SS. Matrix metalloproteinases and their inhibitors in pulmonary hypertension. Eur Respir J 2012;40:766-82.

7. Lepetit H, Eddahibi S, Fadel E, Frisdal E, Munaut C, Noël A, et al. Smooth muscle cell matrix metalloproteinases in idiopathic pulmonary arterial hypertension. Eur Respir 2005;25:834-42.

8. Bishop-Bailey D, Bystrom J. Emerging roles of peroxisome proliferator-activated receptor-beta/delta in inflammation. Pharmacol Ther 2009;124:141-50.

9. Keshamouni VG, Arenberg DA, Reddy RC, Newstead MJ, Anthwal S, Standiford TJ. PPAR-gamma activation inhibits angiogenesis by blocking ELR+CXC chemokine production in non-small cell lung cancer. Neoplasia 2005;7:294-301.

10. Shinzato T, Ohya $Y$, Nakamoto M, Ishida A, Takishita S. Beneficial effects of pioglitazone on left ventricular hypertrophy in genetically hypertensive rats. Hypertens Res 2007;30:863-73.

11. Lee CS, Kwon YW, Yang HM, Kim SH, Kim TY, Hur J, et al. New mechanism of rosiglitazone to reduce neointimal hyperplasia: activation of glycogen synthase kinase-3beta followed by inhibition of MMP-9. Arterioscler Thromb Vasc Biol 2009;29:472-9.

12. Zhang HL, Xu M, Wei C, Qin AP, Liu CF, Hong LZ, et al. Neuroprotective effects of pioglitazone in a rat model of permanent focal cerebral ischemia are associated with peroxisome proliferator-activated receptor gamma-mediated suppression of nuclear factor-kappaB signaling pathway. Neuroscience 2010;176:381-95.

13. Sen U, Rodriguez WE, Tyagi N, Kumar M, Kundu S, Tyagi SC. Ciglitazone, a PPARgamma agonist, ameliorates diabetic nephropathy in part through homocysteine clearance. Am J Physiol Endocrinol Metab 2008;295:1205-12.

14. Rodriguez WE, Joshua IG, Falcone JC, Tyagi SC. Pioglitazone prevents cardiac remodelling in high-fat, high-calorie-induced Type 2 diabetes mellitus. Am J Physiol Heart Circ Physiol 2006;291:81-7.

15. Burrage PS, Schmucker AC, Ren Y, Sporn MB, Brinckerhoff CE. Retinoid $\mathrm{X}$ receptor and peroxisome proliferatoractivated receptor-gamma agonists cooperate to inhibit matrix metalloproteinase gene expression. Arthritis Res Ther 2008;10:139.

16. Shen B, Chu ES, Zhao G, Man K, Wu CW, Cheng JT, et al. PPARgamma inhibits hepatocellular carcinoma metastases in vitro and in mice. Br J Cancer 2012;106:1486-94.
17. Ringseis R, Schulz N, Saal D, Eder K. Troglitazone but not conjugated linoleic acid reduces gene expression and activity of matrix-metalloproteinases-2 and -9 in PMA-differentiated THP-1 macrophages. J Nutr Biochem 19, 594-603.

18. Ameshima S, Golpon $\mathrm{H}$, Cool CD, Chan D, Vandivier RW, Gardai SJ. Peroxisome proliferator-activated receptor gamma (PPARgamma) expression is decreased in pulmonary hypertension and affects endothelial cell growth. Circ Res 2003;92:1162-9.

19. Polikandriotis JA, Mazzella LJ, Rupnow HL, Hart CM. Peroxisome proliferator-activated receptor gamma ligands stimulate endothelial nitric oxide production through distinct peroxisome proliferator-activated receptor gamma-dependent mechanisms. Arterioscler Thromb Vasc Biol 2005;25:1810-16.

20. Nisbet RE, Sutliff RL, Hart CM. The role of peroxisome proliferator-activated receptors in pulmonary vascular disease. PPAR Res 2007;2007:18797.

21. Li HH, Hsu HH, Chang GJ, Chen IC, Ho WJ, Hsu PC, et al. Prostanoid EP4 agonist L-902,688 activates PPARgamma and attenuates pulmonary arterial hypertension. Am J Physiol Lung Cell Mol Physiol 2017:314:349-59.

22. Hansmann G, Wagner RA, Schellong S, de Jesus Perez VA, Urashima T, Wang L, et al. Pulmonary arterial hypertension is linked to insulin resistance and reversed by peroxisome proliferator-activated receptor-gamma activation. Circulation 2007; 115:1275-84.

23. Hansmann G, de Jesus Perez VA, Alastalo TP, Alvira CM, Guignabert C, Bekker JM, et al. An antiproliferative BMP-2/ PPARgamma/apoE axis in human and murine SMCs and its role in pulmonary hypertension. J Clin Invest 2008;118:184657.

24. Wang S, Dougherty EJ, Danner RL. PPARgamma signaling and emerging opportunities for improved therapeutics. Pharmacol Res 2016;111:76-85.

25. Matsuda Y, Hoshikawa Y, Ameshima S, Suzuki S, Okada $\mathrm{Y}$, Tabata $\mathrm{T}$, et al. Effects of peroxisome proliferatoractivated receptor gamma ligands on monocrotaline-induced pulmonary hypertension in rats. Nihon Kokyuki Gakkai Zasshi 2005;43:283-8.

26. Crossno Jr JT, Garat CV, Reusch JE, Morris KG, Dempsey EC, McMurtry IF, et al. Rosiglitazone attenuates hypoxia-induced pulmonary arterial remodelling. Am J Physiol Lung Cell Mol Physiol 2007;292:885-97.

27. Nisbet RE, Bland JM, Kleinhenz DJ, Mitchell PO, Walp ER, Sutliff RL, et al. Rosiglitazone attenuates chronic hypoxiainduced pulmonary hypertension in a mouse model. Am J Respir Cell Mol Biol 2009;42:482-90.

28. Zhang D, Wang G, Han D, Zhang Y, Xu J, Lu J, et al. Activation of PPAR-gamma ameliorates pulmonary arterial hypertension via inducing heme oxygenase-1 and $\mathrm{p} 21(\mathrm{WAF} 1)$ : an in vivo study in rats Life Sci 2014;98:39-43.

29. Kim EK, Lee JH, Oh YM, Lee YS, Lee SD. Rosiglitazone attenuates hypoxia-induced pulmonary arterial hypertension in rats. Respirology 2010;15:659-68.

30. Liu Y, Tian XY, Mao G, Fang X, Fung ML, Shyy JY, et al. Peroxisome proliferator-activated receptor-gamma ameliorates pulmonary arterial hypertension by inhibiting 5-hydroxytryptamine 2B receptor. Hypertension 2012:60:14718.

31. Lu X, Murphy TC, Nanes MS, Hart CM. PPAR \{gamma regulates hypoxia-induced Nox4 expression in human pulmonary artery smooth muscle cells through NF- $\{$ kappa $\}$ B. Am J Physiol Lung Cell Mol Physiol 2010;299:559-66. 
32. Gong K, Xing D, Li P, Aksut B, Ambalavanan N, Yang Q, et al. Hypoxia induces downregulation of PPAR-gamma in isolated pulmonary arterial smooth muscle cells and in rat lung via transforming growth factor-beta signaling. Am J Physiol Lung Cell Mol Physiol 2011;301:L899-907.

33. Xie X, Wang G, Zhang D, Zhang Y, Zhu Y, Li F, et al. Activation of peroxisome proliferator-activated receptor gamma ameliorates monocrotaline-induced pulmonary arterial hypertension in rats. Biomed Rep 2015;3:537-542.

34. Davis GE, Senger DR. Extracellular matrix mediates a molecular balance between vascular morphogenesis and regression. Curr Opin Hematol 2008;15:197-203.

35. Johnson JL. Matrix metalloproteinases: influence on smooth muscle cells and atherosclerotic plaque stability. Expert Rev Cardiovase Ther 2007;5:265-82.

36. Schermuly RT, Kreisselmeier KP, Ghofrani HA, Samidurai A, Pullamsetti S, Weissmann N, et al. Antiremodelling effects of iloprost and the dual-selective phosphodiesterase 3/4 inhibitor tolafentrine in chronic experimental pulmonary hypertension. Circ Res 2004;94:1101-8.

37. Vieillard-Baron A, Frisdal E, Eddahibi S, Deprez I, Baker $\mathrm{AH}$, Newby AC, et al. Inhibition of matrix metalloproteinases by lung TIMP-1 gene transfer limits monocrotaline-induced pulmonary vascular remodelling in rats. Hum Gene Ther 2003;14:861-69.

38. Okada M, Harada T, Kikuzuki R, Yamawaki H, Hara Y. Effects of telmisartan on right ventricular remodelling induced by monocrotaline in rats. J Pharmacol Sci 2009;111:193-200.

39. Hiremath J, Thanikachalam S, Parikh K, Shanmugasundaram S,
Bangera S, Shapiro L, et al. Exercise improvement and plasma biomarker changes with intravenous treprostinil therapy for pulmonary arterial hypertension: a placebo-controlled trial. J Heart Lung Transplant 2009;29:137-49.

40. Umar S, Hessel M, Steendijk P, Bax W, Schutte C, Schalij $\mathrm{M}$, et al. Activation of signaling molecules and matrix metalloproteinases in right ventricular myocardium of rats with pulmonary hypertension. Pathol Res Pract 2007;203:86372.

41. Liu Y, Tian XY, Huang Y, Wang N. Rosiglitazone Attenuated Endothelin-1-Induced Vasoconstriction of Pulmonary Arteries in the Rat Model of Pulmonary Arterial Hypertension via Differential Regulation of ET-1 Receptors. PPAR Res 2014;2014:374075.

42. Kozłowska H, Baranowska-Kuczko M, Schlicker E, Kozłowski M, Kloza M, Malinowska B. Relaxation of human pulmonary arteries by PPARgamma agonists. Naunyn Schmiedebergs Arch Pharmacol 2013;386:445-53.

43. Amberg GC, Navedo MF. Calcium dynamics in vascular smooth muscle. Microcirculation 2013;20:281-9.

This is an open access article distributed under the terms of the Creative Commons Attribution-NonCommercial-ShareAlike 3.0 License, which allows others to remix, tweak, and build upon the work non-commercially, as long as the author is credited and the new creations are licensed under the identical terms

\begin{tabular}{l}
$\begin{array}{l}\text { This article was originally published in a special issue, } \\
\text { "Biomedical Research in Clinical and Preclinical } \\
\text { Pharmaceutics" Indian J Pharm Sci 2020:82(3)Spl issue7;10-18 }\end{array}$ \\
\hline
\end{tabular}

